\title{
sciendo
}

\section{THE WELFARE STATUS OF HENS IN DIFFERENT HOUSING SYSTEMS - A REVIEW*}

\author{
Ewa Sosnówka-Czajka ${ }^{1 *}$, Iwona Skomorucha ${ }^{2}$, Eugeniusz Herbut ${ }^{3}$ \\ Department of Poultry Breeding, National Research Institute of Animal Production, \\ 32-083 Balice n. Kraków, Poland \\ •Corresponding author: ewa.sosnowka@iz.edu.pl \\ ${ }^{1}$ ORCID ID: 0000-0003-3720-1685 \\ ${ }^{2}$ ORCID ID: 0000-0003-1241-7703 \\ ${ }^{3}$ ORCID ID: 0000-0002-7373-3665
}

\begin{abstract}
The currently used poultry farming methods, which aim to maximise economic profit, are based on ever new technological solutions that improve flock management and increase bird performance. However, they do not always meet the natural needs of birds. Every housing method and technological solution currently in use is faced with some issues, such as social stress, adverse temperature/humidity conditions, risk of zoonoses, and behavioural pathologies, which determine poultry performance and welfare. Disregard for animal welfare involves not only ethical but also practical aspects, because well-being and housing comfort translate into better weight gains, health and productivity of the birds. The studies reported here suggest that every production system, despite the many welfare-improving aspects, causes numerous behavioural, productivity and health abnormalities in laying hens. Therefore, further research is needed to identify various risk factors for the purpose of improving housing systems and increasing the welfare of hens.
\end{abstract}

Key words: laying hens, housing systems, welfare, behaviour

The welfare of hens has attracted the interest of scientists, breeders and consumers for many years. Large commercial layer farms are characterised by high stocking density, often with cage housing systems, lack of free range, and thus restriction of movement and considerable mechanisation of bird handling. This may cause stress, behavioural and physiological abnormalities, which has a negative impact on the production and health results (Bessei, 2005; Barnett et al., 2009). It is still not possible to objectively and conclusively determine the welfare status of hens because welfare is the outcome of many factors that affect birds, and their interactions are

*Work financed from statutory activity, project no. 01-12-04-11. 
often equivocal and not entirely understood. Poultry welfare is dependent, among other things, on diseases (e.g. skeletal and foot health), genetics, behaviour, flock size, housing system, prevalence of pests and parasites, the level and duration of stress, flock management and handling procedures, and even the climate zone where the poultry house is located.

Layer management in commercial production of eggs remains a subject of considerable controversy and discussion in the scientific community and society as a whole. Despite the fact that EU legislation provides for different layer housing systems that meet the bird welfare requirements, some of them - in particular the cage system - are associated with many negative opinions, especially among consumers. Many research studies focus on alternative housing systems to improve layer health and welfare while optimising production management and performance, with high quality eggs being of overriding importance (Schwaiger et al., 2008; Jones et al., 2016).

Behavioural assessment is an indispensable component of assessing the wellbeing of birds. As reported by Appleby et al. (2004), restriction of species-, age- and sex-specific behaviour patterns of poultry kept under intensive conditions may lead to physical and mental suffering, as reflected in abnormal forms of behaviour, injuries or diseases. Some of the factors that affect the behaviour of birds are housing system (Anderson et al., 2004; Mishra et al., 2005; Sosnówka-Czajka et al., 2006, 2007; Whay et al., 2007), flock size and stocking density (Albentosa et al., 2007; Sosnówka-Czajka et al., 2007), and microclimate conditions (Herbut et al., 2002; Tuyttens et al., 2005).

The behaviour of birds is determined by their genetic background. Väisänen et al. (2005) assert that modern lines of poultry have poorer social learning capacity with a weaker ability to cope with group disruptions compared to the ancestral breed. In turn, Anderson et al. (2007) observe that long-term selection of layer flocks for increased performance has no effect on their behavioural profile in the subsequent production cycles.

Many studies have also shown differences in the behaviour of hens originating from different commercial lines (Klein et al., 2000; Schütz et al., 2001; Anderson et al., 2004, Weitzenbürger et al., 2006; Sosnówka-Czajka et al., 2011; De Haas et al., 2013; Dudde et al., 2018; Ali et al., 2019; Giersberg et al., 2019; Hewlett and Nordquist, 2019), which is of great practical importance. According to Ali et al. (2016), because hens from different commercial lines show distinct differences in behaviour, when planning to house layers in a given system (e.g. multi-tier aviaries) it is necessary to match furnishings to the commercial layer line. Lee and Chen (2007), based on ethological observations of different local poultry lines, suggest that each of them has different requirements and should be reared in different systems to ensure high welfare levels. Therefore, the aim of this study is to analyze peer-reviewed articles that define the welfare of laying hens in different production systems. The present review discusses the welfare status of hens in enriched cages, followed by single-tier barn systems, and aviary or multi-tier systems. Free range is discussed here as the fourth system. The article reviews the literature from 2000-2020, but the main focus is on the last decade. 


\section{Furnished cage systems}

Battery cages are the world's most popular housing system for laying hens, mainly due to economic reasons (maximum use of the production area of the building and lowest maintenance costs of the hens) (Van Horne and Achterbosch, 2008; Leenstra et al., 2016; Meseret, 2016). Moreover, this system is characterised by considerably lower airborne dust levels compared to the barn system (Rodenburg et al., 2008). Since 1 January 2012, the European Union has banned the housing of laying hens in conventional cages, only allowing the use of enriched cages and non-cage systems (Council Directive 1999/74/EC of 19 July 1999 laying down minimum standards for the protection of laying hens). Kollenda et al. (2020) report that in 2019, around $49.5 \%$ of laying hens in the EU were kept in furnished cages. Furnished (or enriched) cages improve the welfare of laying hens compared to the cages that had been used in the EU before 2012, allowing birds to express natural patterns of behaviour due to the presence of nest, perches, dust baths and scratching areas, as well as providing a greater floor area per bird while maintaining the health and hygienic benefits of conventional cages (Tauson, 2002; Lay et al., 2011; Guinebretière et al., 2012, 2015; Habinski et al., 2017; Meng et al., 2017; Widowski et al., 2017; Hunniford and Widowski, 2018). On the other hand, numerous studies have shown that enrichments in furnished cages may increase the incidence of mechanical injuries (Hester et al., 2013 b; Casey-Trott and Widowski, 2016; Widowski et al., 2017). Not only cage furnishings, but also the type of materials used have a direct effect on bird welfare and behaviour, which may be reflected in production results (Guinebretière et al., 2014).

One of the major forms of layer behaviour is nesting. Hens have a strong instinct for finding a nest to lay eggs (Elson and Croxall, 2006). According to Wall (2011), $95 \%$ of laying hens use nests in cages. However, other studies suggest that nest use varies according to factors such as nest design, cage size, flock size and breed of hens (Guesdon and Faure, 2004; Hunniford et al., 2014; Hunniford and Widowski, 2016, 2017). Guinebretière et al. (2012) reported that the attractiveness of nests depended also on the nest lining. They observed that more hens used nests covered with an artificial turf mat than nests lined with plastic mesh. Frustration and stereotypies were also observed in birds unable to find a nest site. The literature indicates that the aggressive behaviour of hens during egg laying is markedly influenced by competition for nest space (Hunniford and Widowski, 2016, 2017). According to Shimmura et al. (2008), hens in cages with resources (nest box and dust bath) placed on one side of the cage were more aggressive than hens in cages where the resources were more spread out. Many studies have also suggested that cages should be furnished with more than one nest type to meet different preferences of hens and to provide enough space in the nests (Hunniford and Widowski, 2016, 2017, 2018).

Another natural behaviour of laying hens is the perching at different times of the day. Pohle and Cheng (2009) observed that $25-41 \%$ of the birds perched during the day. As reported by Habinski et al. (2017), the behavioural differences among laying hens can be attributed to the differences in physical ability or motivations to use the cage enrichments. 
Numerous studies have demonstrated that perch use by birds is affected by many factors, for example: perch height (Struelens et al., 2008; Thorsten et al., 2010; Yan et al., 2014; Janczak and Riber, 2015; Habinski et al., 2017), cage size and height (Struelens et al., 2008; Meng et al., 2017), age of birds (Enneking et al., 2012; Habinski et al., 2017), perch location within the cage (Habinski et al., 2017) and genetic origin of the hens (Habinski et al., 2017).

Leyendecker et al. (2005) compared enriched cage and aviary systems, while Li et al. (2016) studied different models of enriched cages vs. conventional cages. Both studies showed that furnished cages enhance welfare of hens by reducing stress, aggression, feather pecking, and cannibalism. Likewise, Fossum et al. (2009), who compared hen welfare in different housing systems, found that the incidence of cannibalism was significantly lower in the cage system compared to non-cage systems. Matur et al. (2015) observed a lower heterophil to lymphocyte ratio (H:L) in the blood of hens housed in furnished cages compared to conventionally caged hens, as well as a positive effect of cage enrichments on the immune system of laying hens. In turn, Fossum et al. (2009) noted a lower incidence of bacterial, viral and parasitic diseases in caged hens, leading to a much lower mortality percentage in relation to barn and free-range layers. Rearing in furnished cages generally had a positive effect on bone strength (Meng et al., 2017) and mineral density (Casey-Trott et al., 2017) when compared to old-type cages, which is explained by higher locomotor activity and the provision of perches. Tactacan et al. (2009), who compared laying hen welfare in furnished and conventional cages generally observed no differences in layer performance, feather condition and parameters of immune response. But they did find better bone quality in the hens housed in furnished cages, which they attributed to higher activity of the birds resulting from increased cage area per bird. Likewise, Rodenburg et al. (2008), who compared the welfare of 60-week-old layers housed in furnished cage vs. barn systems found lower mortality and lower incidence of bone fractures in birds from furnished cages.

Keel bone fractures and deformities are a significant factor that negatively affects the health condition, welfare and productivity of laying hens in modern production systems (Nasr et al., 2013; Gebhardt-Henrich et al., 2017; Rørvang et al., 2019; Rufener et al., 2019; Wei et al., 2019). One of the main factors increasing the incidence of keel fractures is the housing system of laying hens (Eusemann et al., 2018). Wilkins et al. (2011) found keel bone fractures to be less frequent in furnished cages compared to barn and free-range systems. Also Eusemann et al. (2018) reported lower incidence of keel fractures in caged hens compared to the barn system. According to Petrik et al. (2015), keel bone fractures are generally least frequent in conventional cages. This is confirmed by the study of Hester et al. (2013 a), who showed that perch use in furnished cages increases keel deformities and fractures compared to conventional cages. In addition, Wilkins et al. (2011) found that perch housing systems contribute to greater incidence of keel bone fractures, and perch height is positively correlated with frequency of fractures. In turn, Casey-Trott and Widowski (2016) showed that keel bone fractures had an effect on the behaviour of hens in furnished cages by reducing their walking activity. 
With proper farm management, enriched cages ensure high level of hygiene and maximize the use of poultry house space, which improves the economic indicators of egg production. Nonetheless, enriched cages offer less freedom of movement compared to non-cage systems, thus reducing the welfare of hens.

\section{Single-tier barn systems}

Barn management provides layers with markedly greater freedom of movement compared to cages, even furnished ones. Under this system, birds are kept on bedding, which is replenished as needed throughout rearing. Legal regulations (Council Directive 1999/74/EC of 19 July 1999 laying down minimum standards for the protection of laying hens) in European Union countries require that at least one-third of floor area should be covered with bedding material and the poultry house should be furnished with nests and perches.

The litter is a critical component of the environment of poultry facilities because it has an effect on indoor climate, especially temperature/humidity conditions, dust levels, airborne microflora, and the concentration of harmful gaseous substances (Sosnówka-Czajka et al., 2008). In single-tier barn systems, care should be taken to regularly replenish litter to prevent it from becoming too moist, which also indirectly affects hens' health and productivity. According to van Staaveren et al. (2018), infrequent removal of manure in single-tier systems increases ammonia levels compared to free-range and enriched cage systems, which has a negative effect on layer welfare. As reported by Guinebretière et al. (2014), the type of litter has a distinct effect on the behaviour of laying hens. Van Staaveren et al. (2018) reported that in single-tier systems, the most commonly used litter substrates were sawdust $(44.4 \%)$ and wood shavings $(22.2 \%)$.

The barn system allows birds not only free movement, but above all natural scratching behaviour. Rodenburg et al. (2008), who compared the welfare of 60 -week-old laying hens housed in the barn and furnished cage systems, showed that barn layers are more active, more prone to scratching, make more frequent use of perches, and are less fearful. Decina et al. (2019) confirmed the importance of litter access for layer welfare. The researchers found higher incidence of feather damage in layers raised on wire mesh floor and slatted floor compared to litter floor. Van Staaveren et al. (2018), who evaluated different layer management systems in Canada in 2016-2017, showed that more than 50\% of non-cage single-tier housing systems provided no litter, of which $20 \%$ had a fully slatted barn without litter. Only $12.5 \%$ of the single-tier systems were all litter barns.

A serious concern in the poultry industry are leg disorders and bone injuries in laying hens (Heerkens et al., 2016 a). Bone injuries are considered painful, reducing birds' activity levels and having adverse effects on feed conversion and egg quality (Nasr et al., 2013, 2014; Heerkens et al., 2016 a). Sherwin et al. (2010) demonstrated that barn layers were characterised by the highest prevalence of fractures and emaciation, as well as the highest corticosterone concentration in relation to birds from conventional cage, furnished cage and free-range systems. Petrik et al. (2015) found that keel fractures were more frequent in flocks of barn hens compared to caged hens (48.3\% vs. 24.8\%). Also Wilkins et al. $(2004 ; 2011)$ reported high frequency of bone 
fractures in hens raised in litter floor systems. Gebhardt-Henrich et al. (2017) and Toscano et al. (2018) observed that one of the most frequent causes of comb damage in layers from litter floor systems were collisions with structural elements (nests, feeders, waterers, perches), falls from perches as well as bone injuries and deformations due to excessive loading of birds sitting on the perch. Hence Pettersson et al. (2017), assuming that collisions and the resulting keel bone damage are prevalent in both barn and free-range systems, investigated two types of ramps (grid ramps made of plastic poultry slats, and ladder ramps made of wooden rungs) to evaluate the behaviour and preferences of hens. They concluded that hens preferred the plastic slats for walking on, which caused fewer fractures and collisions. The wooden rungs were mainly used by the birds as perches to rest or sleep. Therefore, to increase the welfare status of hens raised in the barn system, it is important to suit house furnishings to bird preferences, while making them from materials that minimise mortality or body injuries.

Fossum et al. (2009) compared laying hen welfare in different housing systems and found significantly higher incidence of bacterial, viral and parasitic diseases as well as cannibalism in the barn system than in the cage system. In Swedish layer farms, these authors most often diagnosed colibacillosis, erysipelas, coccidiosis, red mite infestation, lymphoid leucosis and cannibalism. Less frequent was the incidence of Newcastle disease, pasteurellosis, and botulism. Therefore, to improve layer health in litter farms, special attention should be directed to flock management, biosecurity and vaccinations. According to Fossum et al. (2009), hen mortality is much higher in the barn system than in the cage system, with cannibalism being one of the main causes of death in the barn system.

No or difficult access to nest sites deprives hens of their basic needs, which increases frustration and stereotypies, leading to higher aggression (Elson and Croxall, 2006). Villanueva et al. (2017) report that at peak egg laying time, birds very often crowd near or in nests, which increases frustration and compromises layer welfare. Nesting behaviour before and during laying may be also dependent on breed or even commercial line of hen (Ali et al., 2016). Singh et al. (2009), who studied commercial lines of laying hens housed in the barn system, concluded that frequency of nest use and of laying eggs outside the nest depends on layer genotype, and the genotype by environment interaction is very high and should be considered in alternative housing systems.

Feather damage due to feather pecking or inadequate enrichments/housing system constitutes a major problem for poultry producers around the world. Plumage damage is indicative of reduced welfare status of the birds and is negatively perceived by consumers. Riber and Hinrichsen (2016), when studying the relationship between feather eating and feather pecking in the barn and organic systems, showed a higher proportion of hens with poor feather condition in the barn system $(22.2 \%)$ compared to organically raised birds (7.4\%). Also Sherwin et al. (2010) compared hen welfare in different systems (conventional cages, enriched cages, barn system, barn system with outdoor access) and concluded that barn layers were characterised by the poorest feather score.

As already noted, the origin of birds determines their behaviour and adaptation to different housing systems. Mahboub et al. (2004) demonstrated the differences in 
the behaviour of birds of two different commercial lines. Also, in the case of native breed hens, genetic origin influences bird behaviour, as confirmed by Uitdehaag et al. $(2008,2009)$ in the study concerning the behaviour of Rhode Island Red and Leghorn laying hens. In addition, Sosnówka-Czajka et al. (2011), based on behaviour and mortality, evaluated differences in the welfare status of native breed hens such as the Yellowleg Partridge, Sussex, Leghorn, as well as commercial hybrids ISA Brown, Lohmann Brown and Hy-Line, which were housed in the barn system. The authors showed that out of the three commercial layers from the barn system, the poorest welfare was characteristic of ISA Brown birds. It was also demonstrated that Sussex hens from the barn system had better welfare status than Yellowleg Partridge and Leghorn hens.

According to El-Lethey et al. (2001), stress affects the behaviour of birds. Native breed hens (primitive breeds) are best adapted to housing with outdoor access, while confined housing (barn and cage systems) increases stress, which in the study of Sosnówka-Czajka et al. (2011) was manifested in increased mortality and higher aggressiveness compared to commercial layers, which have a high tolerance for the barn housing system. These results are supported by Wiren et al. (2009), who stated that the domestication of poultry and the intensive selection for improved performance reduced the level of aggression in high-producing birds compared to the native breeds. According to Nielsen et al. (2003), native breed hens are much more active than the commercial lines of poultry, which spend more time lying and feeding. However, Sosnówka-Czajka et al. (2011) generally observed no differences in walking activity between native layers and commercial layers.

Single-tier barn systems are a good alternative to the cage system in laying hen management because they enable more freedom of movement and allow for scratching and litter pecking, which is beneficial to bird welfare. However, to maintain a high welfare status of hens in this system, it is recommended to pay special attention to proper genetic selection of birds, litter quality, furnishings and biosecurity.

\section{Aviary or multi-tier systems}

Egg production makes an increasing use of multi-tier floor system known as the multi-tier or aviary system. This system is growing in popularity as it improves production efficiency and functionality in relation to conventional egg production in the single-tier floor system, as well as considerably improving bird welfare when compared to cage housing. The aviary system takes advantage of the poultry house potential, increasing the usable area. This solution may satisfy the preferences of hens for different heights or different floor types. It provides additional space and resources for the hens, including floor litter. The distribution of hens in this system is influenced by flock behaviour, space allowance and physical distribution of perches, litter, nests, platforms, feed and water. These systems are specially designed to allow hens to express their natural behaviours (nesting, perching, foraging, dust bathing), which improves the comfort of birds. Today, many companies offer systems which are fully automated and adapted to rearing without access to pasture, aviaries, or with outdoor access. Accordingly, the scientific literature contains many studies concerning this rearing system (Regmi et al., 2015; Campbell et al., 2016 a, b; Ali et al., 
2019). Van Staaveren et al. (2018) found that the multi-tier systems used in Canada in 2016-2017 consisted of three (50.0\%) or two tiers (36.4\%), while $13.7 \%$ had more than three tiers.

Riddle et al. (2018) evaluated the spatial requirements of different commercial layer lines in terms of five basic behaviours. The experiment, which used 28-weekold Hy-Line Brown, Bovans Brown, DeKalb White and Hy-Line W36 layers, examined the spatial requirements during standing, lying, perching, wing flapping and dust bathing on an open-litter area in a commercial-style aviary between 12:00 and 15:00. Brown hens required more space for standing, lying and dust bathing than white hens. White hens used more space to perform wing flapping. Both white and brown hens were wider while perching than the $15 \mathrm{~cm}$ commonly recommended per hen, but brown hens required much more perch space than white hens. The absence of perches and thwarted access to perches increase frustration in layers, while perch material and physical distribution of perches influence the welfare status of birds. This has led to a large number of studies on perches in multi-tier aviary systems (Käppeli et al., 2011; Stratmann et al., 2015; Campbell et al., 2016 a; Sirovnik et al., 2018), most of which concluded that during nocturnal rest, hens prefer upper tier perches (Brendler et al., 2014; Campbell et al., 2016 b; Ali et al., 2019). Considering the above results and the different preferences and behaviours of hens of different genetic origin, it is recommended that these data should be accounted for in industry guidelines, legal regulations and when designing and stocking poultry houses, so as to satisfy the behavioural needs of layers as much as possible.

Heerkens et al. (2016 a) report that hen welfare in multi-tier aviary systems may be impaired due to increased risk of keel bone injuries (flock mean prevalence in 60 -week-old layers: wounds $17.6 \%$, haematomas $41.2 \%$, fractures $82.5 \%$ and deviations 58.9\%) and foot pad injuries (flock mean prevalence in 60-week-old layers: dermatitis $27.6 \%$, hyperkeratosis $42.0 \%$ ). Identified risk factors for these disorders were aviary type, perch, nest and tier flooring material, free-range availability and corridor width. In addition, Stratmann et al. (2016), who assessed two different multi-tier system designs, demonstrated the impact of design on incidence of keel bone damage, body weight and layer mortality. According to Fleming et al. (2006), alternative housing systems such as aviaries allow for greater freedom to move and fly, which likely leads to a higher incidence of keel bone fractures due to high energy collisions in these systems. Heerkens et al. (2015) decided to identify risk factors for increased mortality and feather pecking in hens housed in multi-tier aviaries. Wire mesh aviaries and freerange systems improved hen welfare, as evidenced by better plumage condition and lower mortality compared to aviaries with plastic slatted flooring or houses without a free-range area. Furthermore, the hens in aviaries with wire mesh flooring had fewer wounds and better laying performance compared to the hens in plastic slatted aviaries, which was due to better hygiene associated with wire mesh flooring.

Heerkens et al. (2016 b) undertook a study on the modification of multi-tier systems to reduce the incidence of keel bone and foot pad disorders in laying hens. Ramps between perches and nests reduced keel bone fractures and deviations and foot pad injuries in layers. Keel bone and foot pad disorders were found to be related to genetic predisposition. 
Neijat et al. (2019) compared the effect of a multi-tier aviary, conventional and enriched cages on bone quality in laying hens. Total bone weight and ash content were lowest in hens kept in conventional cages, and there were no differences in the bone parameters between the multi-tier aviary and enriched cage systems. In a similar study, Regmi et al. (2017) found that housing layers in a multi-tier system or enriched colony cages had a positive effect on bone quality compared to housing in conventional cages. The same study also showed a beneficial effect of the aviary system compared to enriched cages on bone quality parameters of the birds.

According to van Staaveren et al. (2018), all multi-tier farms in Canada (2016-2017) provided litter access, with 6.7\% having less than one-third of the barn covered with litter, 33.3\% had one-third of the barn with litter, and $60 \%$ had more than one-third of the barn provided with litter. The most popular litter substrates were wood shavings $(52.6 \%)$ and sawdust $(10.5 \%)$. In as much as $25 \%$ of the multi-tier systems, manure was used as a litter substrate. In turn, Campbell et al. (2017 a), who investigated the effect of various flooring types (straw litter, wood shavings, plastic turf mats) in a tiered aviary on foraging and dust bathing in laying hens, concluded that plastic turf is suitable for nest boxes, but straw and shavings are more ideal litter substrates. Different results were obtained by Regmi et al. (2018) for different types of litter substrates (Astroturf, straw, wood shavings) and flooring (bare concrete floor) used in the multi-tier aviary. No effects of the litter substrate/flooring on productivity and physical parameters of layer welfare are observed. Oliveira et al. (2019) studied the effect of part-time litter access (from 10:50 to 21:00) in Dekalb White hens housed in an aviary with 50,000-hen nominal capacity. Limiting litter access of the hens was motivated by a practice of egg producers who temporarily confine the hens in the aviary system during oviposition period in the early morning so as to reduce the number of eggs laid outside the nest. Limited litter access had no effect on hen welfare conditions, mortality and body weight. In the hens with part-time litter access, there was lower incidence of floor eggs as well as lower aerial ammonia concentration due to drier litter.

To sum up, this housing system, with proper management, not only meets the behavioural needs of laying hens, but also maximises the use of poultry house space, which has a beneficial effect on both bird welfare and economic results.

\section{Free-range system}

Housing with outdoor access has become increasingly popular in recent years. This rearing system potentially has the most favourable effect on bird welfare as it allows hens to display the full range of behaviours both in the barn and in the free range, which improves the comfort of birds (Tuyttens et al., 2005; Lay et al., 2011). Rodriguez-Aurrekoetxea and Estevez (2016) reported other advantages of the freerange system associated with welfare benefits such as better plumage, reduced keel bone fractures and lower risk of feather pecking. However, Mahboub et al. (2004) and Icken et al. (2008) observed that the frequency of the outside run visits and the use of the outdoor range vary according to breed which, according to Campbell et al. (2018), is contributed to by differences in fear responses. Numerous studies have also pointed to a great deal of other environmental and social factors, such as climate 
conditions, time of day, flock size and age of hens, which influence the frequency of outside run visits (Hegelund et al., 2005; Richards et al., 2011; Gilani et al., 2014; Rodriguez-Aurrekoetxea and Estevez, 2016; Larsen et al., 2017).

Rodriguez-Aurrekoetxea and Estevez (2016) reported that hens in a flock would differ in individual patterns of outdoor space use. Hegelund et al. (2005), who evaluated the hens' use of range area in conventional and organic free-range systems, found that on average $9 \%$ of the flock used the range area. On the other hand, Richards et al. (2011) and Gebhardt-Henrich et al. (2014) observed that $8 \%$ of the flock never use the range area and the use of free-range varied according to the group of hens in the flock. Similar results were obtained by Campbell et al. (2017 b), who showed that $10 \%$ of the layers never accessed the range, while the other hens varied in their range use. In a more recent study, Campbell et al. (2017 c) compared different outdoor stocking densities (2,000 hens/ha, 10,000 hens/ha and 20,000 hens/ ha) and concluded that only $2 \%$ of the hens in each density never ventured outdoors. The proportion of hens that used the range daily was $80.5 \%$ for a stocking density of 2,000 hens/ha, $66.5 \%$ for 10,000 hens/ha, and $71.4 \%$ for the highest density of 20,000 hens/ha. The authors showed that, on average, $38 \%$ to $48 \%$ of hens were seen on the range simultaneously and this concerned all of the experimental groups under study. In turn, Rodriguez-Aurrekoetxea and Estevez (2016) reported that only 50\% of the flock used the outdoor runs. Singh et al. (2017) found that over 75\% of freerange hens raised in Australia use the range area.

Hartcher et al. (2016) investigated range use by 26-week-old ISA Brown hens and showed that $95 \%$ of the birds accessed the outdoor run more than once per day. Birds spent an average duration of $6.1 \mathrm{~h}$ outside each day, with over 11 visits per bird per day (51.5 min per visit). According to Singh et al. (2017), layers spend up to $75 \%$ of the day on the range.

Many studies have also shown that most of hens only use the range area located close to the hen house (Rault et al., 2013; Steenfeldt and Nielsen, 2015; Chielo et al., 2016). Good results in adapting adult hens to greater use of free-range space can be achieved by releasing the birds outside from the start of rearing (Sosnówka-Czajka et al., 2006; Janczak and Riber, 2015). Also, Rodriguez-Aurrekoetxea and Estevez (2016) demonstrated that the early experience of the hens using the outdoor area determined the level of use of the outdoor area at later ages. In turn, Gilani et al. (2014) reported that birds range away from the house more as they get older, probably due to grass quality, which decreases close to the house after a certain time of production, hence birds move away to find better quality vegetation.

The number of ranging hens also depends on the time of day. Mahboub et al. (2004) and Nagle and Glatz (2012) indicated that hens are more active in the evening (the period of most intensive foraging activity) than at noon. Larsen et al. (2017) observed a lower percentage of ranging hens during the day (at around 13:00) and in late afternoon (around 17:00), and the highest percentage right after the range was opened (around 10:00) and in the afternoon (around 15:00). The authors also concluded that the average time spent on the range was longer in the morning and at noon, and shorter in the afternoon. In turn, Rodriguez-Aurrekoetxea and Estevez (2016) noted a lower proportion of ranging hens around noon than in the morning and afternoon. 
Mahboub et al. (2004) believe that in hens from large flocks, outdoor access may have a positive effect on their welfare by reducing the number of aggressive behaviours. Campo et al. (2013) found mortality of laying hens raised in the freerange system to be higher due to feather picking and cannibalism when compared to the barn system. Fossum et al. (2009) compared hen welfare in different housing systems and showed that hen mortality is considerably higher in the free-range system than in the cage system, with cannibalism being one of the main causes of death in the free-range system. In turn, Sherwin et al. (2010) found that vent pecking was more prevalent in free-range hens than in hens housed in conventional or furnished cages. Grafl et al. (2017) observed better plumage and better feather condition in the summer in free-range hens. This is consistent with the Bestman and Wagenaar (2014), who demonstrated that outdoor access is beneficial to birds because it is associated with lower feather pecking. Behavioural analysis of hens showed the highest dust bathing and foraging activity (scratching followed by ground pecking) in the free range, and the most frequent resting activity in the hen house (Campbell et al., 2017 b).

Hegelund et al. (2005) observed that in practice free-range farming might cause health problems in birds, especially when the range is improperly used. Likewise, Fossum et al. (2009) demonstrated the higher risk of infectious diseases and cannibalistic behaviours in barn compared to caged hens; however, according to the authors, the negative impact on layer health should be attributed to litter as a potential source of pathogens and not to the outdoor access.

The red mite, Dermanyssus gallinae, is common in poultry farms, where it occasionally leads to death. The presence of this parasite is associated with compromised welfare in birds and with reduced production efficiency (Guy et al., 2004; Kilpinen et al., 2005; Wang et al., 2019). According to Fiddes et al. (2005) and Guy et al. (2004), free-range hens are more often exposed to red mite than hens in other housing systems. Höglund et al. (1995) evaluated the effects of the red mite in Swedish farms. The authors showed that only $4 \%$ of the cage systems were infected with this parasite, compared to $21-33 \%$ in deep-litter systems and $19-67 \%$ in free-range systems. The presence of red mite on a poultry farm also causes behavioural changes in hens. According to Kilpinen et al. (2005), mite-infected layers exhibited more frequent self-grooming and head scratching both during the day and night. Moreover, Campo et al. (2013) and Rodriguez-Aurrekoetxea and Estevez (2016) reported that free-range system increased the risk of parasitic infections and some diseases, while Lay et al. (2011) and Gilani et al. (2014) pointed to the problem of predators, the presence of which increases stress levels in free-range birds.

The range area should be equipped with drinkers and sheltered perches to protect birds from bad weather and predatory animals (Gilani et al., 2014). Van Staaveren et al. (2018) reported that in 2016-2017 in Canada, outdoor access was provided to $20.5 \%$ of layer flocks from non-cage systems, and the birds were around 28 weeks old when first given access to the outdoor area. It is notable that $75 \%$ of the outdoor areas were provided with natural or artificial shelters. In turn, Donaldson and O'Connell (2012) demonstrated that the provision of range areas with aerial perches significantly increased the welfare status of hens in terms of reduced fearfulness 
and aggression, and improved body condition compared to the range areas without perches.

The literature reports that the free-range system has a considerable impact on the avian immune system (Arbona et al., 2011; Kamil et al., 2012; Yang et al., 2014) and may help to reduce stress experienced by poultry under intensive systems (Chen et al., 2013). However, Campo et al. (2013) reported a blood heterophil to lymphocyte $(\mathrm{H}: \mathrm{L})$ ratio of 0.6 in free-range hens, which is indicative of modest stress levels. Shimmura et al. (2010), who compared various layer rearing systems, showed a low $\mathrm{H}: \mathrm{L}$ ratio in free-range hens and the shortest duration of tonic immobility (TI) compared to other housing systems. In addition, Dikmen et al. (2016) noted a lower H:L ratio in free-range hens compared to caged hens, but the birds from these systems showed a similar TI duration. Skomorucha and Sosnówka-Czajka (2017) found the level of stress to decrease, as reflected in lower glucose and corticosterone concentrations in birds with free-range access; this may suggest the higher welfare status of free-range poultry compared to birds kept in the barn system. Lower blood glucose levels in free-range birds were also reported by Gunes et al. (2002) and Rehman et al. (2017).

Reduced stress in free-range farming is also manifested by increased antibody titer. Rehman et al. (2017) noted a considerable influence of the free-range system on increasing antibody titer against Newcastle disease (ND) and infectious bronchitis (IB) vaccines. A positive effect of the free-range system on antibody production is also reported by Arbona et al. (2011) and Kucuky1lmaz et al. (2012).

The literature reports that the performance of laying hens using the range area is generally lower compared to other housing systems (Golden et al., 2012; Leinonen et al., 2012; Singh and Cowieson, 2013; Samiullah et al., 2014), which is probably influenced by energy expenditure also on roaming outdoors and foraging (Meng et al., 2015), or adapting the organism to varying climatic conditions on the free range. However, some studies showed higher egg production in hens from free-range systems (Dikmen et al., 2016), as well as their positive effect on bird health and product quality (Karsten et al., 2010; Mugnai et al., 2013; Chen et al., 2018; Popova et al., 2020).

With proper farm management, the free-range system has the most favourable effect on welfare because it allows birds to display the full range of behaviours both in the barn and in the free range.

\section{Conclusions}

Today, egg production in EU countries and around the world is based on the intensive system (mainly in conventional and furnished cages), barn system, aviaries or free-range systems. Every layer housing method and technological solution is faced with problems such as social stress, adverse temperature/humidity conditions, inability to express the full range of natural patterns of behaviour, risk of zoonoses or behavioural pathologies, which determine poultry performance and welfare.

The studies cited above indicate that genetic origin (predisposition) largely determines hen behaviour, productivity, incidence of bone disorders, foot pad injuries, etc., which may suggest that the simplest way to improve hen welfare is through 
proper choice of breeds and hybrids for specific housing systems and, subsequently, modification of these systems. Sherwin et al. (2010) compared the welfare of laying hens in 4 different housing systems (conventional cage, furnished cage, barn, freerange) and concluded that they had an effect on bird welfare, condition and physiological status, but in each system the authors observed high levels of emaciation, loss of plumage, fractures and stress.

The studies reported here clearly indicate that despite ongoing research on bird welfare, modifications of existing housing systems to improve poultry living conditions, and a large body of legislation, the welfare of present-day poultry is often unsatisfactory and requires further improvements. The numerous studies presented in this article clearly demonstrate that there is no ideal system in terms of hen welfare, each system has its advantages and disadvantages, and not every breed and line is suitable for every system. The choice of production system and layer breed or line must be well considered to minimise the risks and to ensure high performance while maintaining proper welfare status.

As shown in the current study, the complexity of the environment expands the birds behavioural repertoire, but on the other hand it lends itself to different challenges when working to control diseases and parasites; moreover, complex environments may lead to pathological behaviours, which means that the changes made to improve welfare should account for genetic origin of the hens. Additionally, marked behavioural differences between genetic lines underline the importance of using breed-specific flock and welfare management processes. As a consequence, any attempt to evaluate a housing system requires weighing the advantages and disadvantages according to the breed and line of hens. Therefore, when choosing a production system, it is necessary to account for the hen genotype by environment interactions, because rearing systems and their possible modifications influence the well-being and behaviour of birds which, in turn, has an impact on performance.

Because the effect of rearing system on egg quality and hen health is complex due to the many variables, research findings on layer housing systems are often contradictory. Therefore, further research is needed to gain a more comprehensive understanding of layer behaviour, welfare and productivity in different rearing systems.

\section{References}

Albentosa M.J., Cooper J.J., Luddem T., Redgate S.E., E1s on H.A., Walker A.W. (2007). Evaluation of the effects of cage height and stocking density on the behavior of laying hens in furnished cages. Brit. Poultry Sci., 48: 1-11.

A 1 i A.B.A., C a m p be 11 D.L.M., K a r c h e r D.M., S i e g ford J.M. (2016). Influence of genetic strain and access to litter on spatial distribution of 4 strains of laying hens in an aviary system. Poultry Sci., 95: 2489-2502.

A 1 i A.B.A., C a m p be 11 D.L.M., K a r cher D.M., S i e g ford J.M. (2019). Nighttime roosting substrate type and height among 4 strains of laying hens in an aviary system. Poultry Sci., 98: 1935-1946.

Anders on K.E., Davis G.S., Jenkins P.K., Carroll A.S. (2004). Effects of bird age, density, and molt on behavioral profiles of two commercial layer strains in cages. Poultry Sci., 83: 15-23. 
Anderson K.E., Jones D.R., Davis G.S., Jenkins P.K. (2007). Effects of genetic selection on behavioral profiles of Single Comb White Leghorn hens through two production cycles. Poultry Sci., 86: 1814-1820.

A p pleby M.C., Mench J.A., Hughes B.O. (2004). Poultry behaviour and welfare. CABI Publishing, Wallingford, UK.

A r b o n a V., A nders on K.E., H o ffm a n J.B. (2011). A comparison of humoral immune function in response to a killed Newcastle's vaccine challenge in caged vs. free-range Hy-line brown layers. Int. J. Poultry Sci., 10: 315-319.

B a rn e t t J.L., T a u s o n R., D ow n ing J.A., J a n a r d h a n a V., L o w e $n$th a 1 J.W., B u t l e r K.L., Cron in G.M. (2009). The effects of a perch, dust bath, and nest box, either alone or in combination as used in furnished cages, on the welfare of laying hens. Poultry Sci., 88: 456-470.

B e s s e i W. (2005). Welfare of meat producing poultry - an overview. Anim. Sci. Pap. Rep., 23, Suppl. 1: $205-216$.

B e s tman M., Wag en a r J.P. (2014). Health and welfare in Dutch organic laying hens. Animals, 42: 374-390.

B rendler C., K i p per S., S c hra de r L. (2014). Vigilance and roosting behaviour of laying hens on different perch heights Appl. Anim. Behav. Sci., 157: 93-99.

Campbel1 D.L.M., Makagon M.M., Swanson J.C., Siegford J.M. (2016 a). Laying hen movement in a commercial aviary: Enclosure to floor and back again. Poultry Sci., 95: $176-187$.

C a m p be 11 D.L.M., Ma k a g on M.M., S w a n s o n J.C., S i e g ford J.M. (2016 b). Perch use by laying hens in a commercial aviary. Poultry Sci., 95: 1736-1742.

C a m p bell D.L.M., A 1 i A.B.A., K a r c h e r D.M., S i e g for d J.M. (2017 a). Laying hens in aviaries with different litter substrates: Behavior across the flock cycle and feather lipid content. Poultry Sci., 96: 3824-3835.

C a m p bell D.L.M., H in ch G., D ow n ing J., Lee C. (2017 b). Outdoor stocking density in freerange laying hens: Effects on behaviour and welfare. Animal, 11: 1036-1045.

C a m p bell D.L.M., H in ch G., Dyall T., Warin L., Little B., Lee C. (2017 c). Outdoor stocking density in free-range laying hens: Radio-frequency identification of impacts on range use. Animal, 11: 121-130.

Campbel1 D.L.M., Talk A.C., L oh Z.A., D y a 11 T.R., L e e C. (2018). Spatial cognition and range use in free-range laying hens. Animals, 8: 26.

Campo J.L., Cabezas R., Torres O., González Briones I., A lonso C. (2013). Egg quality and welfare of white-tinted-, and brown-shell egg layers in three different non-cage housing systems. Arch. Geflugelkd., 77: 179-188.

C a s e y - Tr o t t T.M., W i d o w s k i T.M. (2016). Behavioral differences of laying hens with fractured keel bones within furnished cages. Front Vet. Sci., 3: 42.

C a s e y - Tr o t t T.M., K orver D., Gu e ri n M.T., S a n d i l a n d s V., Tor rey S., W i d o w s ki T.M. (2017). Opportunities for exercise during pullet rearing Part II: Long-term effects on bone characteristics of adult laying hens at the end-of-lay. Poultry Sci., 96: 2518-2527.

Chen S., Xi ang H., Z h u X., Z hang H., Wang D., Li u H., Wang J., Y in T., Li u L., K o ng M., $\mathrm{Z}$ h a n g J., O g u r a S.I., Z h a o X. (2018). Free dietary choice and free-range rearing improve the product quality, gait score, and microbial richness of chickens. Animals, 8: 84.

Chen X., Jiang W., Tan H.Z., Xu G.F., Zhang X.B., We i S., Wang X.Q. (2013). Effects of outdoor access on growth performance, carcass composition, and meat characteristics of broiler chickens. Poultry Sci., 92: 435-443.

Ch i e lo L.I., P i k e T., C o o p e r J. (2016). Ranging behaviour of commercial free-range laying hens. Animals, 6: 28.

De Haas E.N., Kemp B., Bolhuis J.E., Groothuis T., Rodenburg T.B. (2013). Fear, stress, and feather pecking in commercial white and brown laying hen parent-stock flocks and their relationships with production parameters. Poultry Sci., 92: 2259-2269.

De c ina C., B erke O., van Staaveren N., B a es C.F., Widowski T.M., Harlander- M a t a u s chek A. (2019). A cross-sectional study on feather cover damage in Canadian laying hens in non-cage housing systems. BMC Vet. Res., 15: 435.

D i k m e n B.Y., İ p e k A., Ş a h a n Ü., P e t e k M., S ö z c ü A. (2016). Egg production and welfare of 
laying hens kept in different housing systems (conventional, enriched cage, and free range). Poultry Sci., 95: 1564-1572

D on ald s on C.J., O ' C onnell N.E. (2012). The influence of access to aerial perches on fearfulness, social behaviour and production parameters in free-range laying hens. Appl. Anim. Behav. Sci., 142: 51-60.

Dudd e A., S chrader L., Weigend S., Mat thew s L.R., Kra us e E.T. (2018). More eggs but less social and more fearful? Differences in behavioral traits in relation to the phylogenetic background and productivity level in laying hens. Appl. Anim. Behav. Sci., 209: 65-70.

E 1-Lethey H., Jungi T.W., Huber-Eicher B. (2001). Effects of feeding corticosterone and housing conditions on feather pecking in laying hens (Gallus gallus domesticus). Physiol. Behav., 73: $243-251$.

E 1 s o n H.A., Crox all R.A. (2006). European study on the comparative welfare of laying hens in cage and non-cage systems. Arch. Geflugelkd., 70: 194-198.

Enneking S.A., Cheng H.W., Jefferson-Moore K.Y., Einstein M.E., Rubin D.A., He ster P.Y. (2012). Early access to perches in caged White Leghorn pullets. Poultry Sci., 91: 2114-2120.

Eus e mann B.K., Baulain U., Schrader L., Thöne-Reineke C., Patt A., Petow S. (2018). Radiographic examination of keel bone damage in living laying hens of different strains kept in two housing systems. PLoS One, 13(5): e0194974.

Fiddes M.D., Le Gresley S., Pars ons D.G., Ep e C., Coles G.C., Stafford K.A. (2005). Prevalence of the poultry red mite (Dermanyssus gallinae) in England. Vet. Rec., 157: 233-235.

F le m ing R.H., M c C or m a c k H.A., M c Te ir L., Wh i t e h e a d C.C. (2006). Relationships between genetic, environmental and nutritional factors influencing osteoporosis in laying hens. Brit. Poultry Sci., 47: 742-755.

F o s s u m O., J a n s s o n D.S., E t t e r 1 i n P.E., V å g s h o 1 m I. (2009). Causes of mortality in laying hens in different housing systems in 2001 to 2004. Acta Vet. Scand., 51: 3.

G e bhardt - H en ri ch S.G., Tos c a n o M.J., Fröh li c h E.K.F. (2014). Use of the outdoor ranges by laying hens in different sized flocks. Appl. Anim. Behav. Sci., 155: 74-81.

Gebhardt-Henrich S.G., Pfulg A., Fröhlich E.K.F., Käppeli S., Guggisberg D., Li es e gang A., St offel M.H. (2017). Limited associations between keel bone damage and bone properties measured with computer tomography, three-point bending test, and analysis of minerals in Swiss laying hens. Front. Vet. Sci., 4: 128.

Gi e r s berg M.F., S p ind ler B., Ke mper N. (2019). Linear space requirements and perch use of conventional layer hybrids and dual-purpose hens in an aviary system. Front. Vet. Sci., 6: 231.

Gilani A.M., Knowles T.G., Nic ol J.C. (2014). Factors affecting ranging behaviour in young and adult laying hens. Brit. Poultry Sci., 55: 127-135.

Golden J.B., A rbona D.V. Ander s on K.E. (2012). A comparative examination of rearing parameters and layer production performance for brown egg-type pullets grown for either free-range or cage production. J. Appl. Poultry Res., 21: 95-102.

Grafl B., Polster S., Sulejmanovic T., Pürrer B., Guggenberger B., Hess M. (2017). Assessment of health and welfare of Austrian laying hens at slaughter demonstrates influence of husbandry system and season. Brit. Poultry Sci., 58: 209-215.

Gues d o n V., F a ure J.M. (2004). Laying performance and egg quality in hens kept in standard or furnished cages. Anim. Res., 53: 45-57.

Gu inebretière M., Hun e a u - S a laün A., Hu onnic D., Michel V. (2012). Cage hygiene, laying location, and egg quality: The effects of linings and litter provision in furnished cages for laying hens. Poultry Sci., 91: 808-816.

Guinebretière M., B e yer H., Arnould C., Michel V. (2014). The choice of litter material to promote pecking, scratching and dustbathing behaviours in laying hens housed in furnished cages. Appl. Anim. Behav. Sci., 155: 56-65.

$\mathrm{Gu}$ in e bretière M., M i che 1 V., A r n o u ld C. (2015). Dustbathing, pecking and scratching behaviours of laying hens in furnished cages are enhanced by the presence of rubber mats and litter distribution. Appl. Anim. Behav. Sci., 171: 128-137.

Gun e s N., P o lat U., P e te k M. (2002). Investigation of changes in biochemical parameters of hens raised in alternative housing systems. Uludag. Univ. Ver. Fak. Derg., 21: 39-42. 
G u y J.H., K h a j a vi M., H l a 1 e 1 M.M., S p a r a g a n o O. (2004). Red mite (Dermanyssus gallinae) prevalence in laying units in Northern England. Brit. Poultry Sci., 45, Suppl 1: S15-S16.

Habinski A.M., Caston L.J., Cas ey-Trott T.M., Hunniford M.E., Widowski T.M. (2017). Development of perching behaviour in 3 strains of pullets reared in furnished cages. Poultry Sci., 96: 519-529.

Hartcher K., Hi ckey K., He m sw orth P., Cronin G., Wilkin son S., S ingh M. (2016). Relationships between range access as monitored by radio frequency identification technology, fearfulness, and plumage damage in free-range laying hens. Animal, 10: 847-853.

He erkens J.L.T., D e le zi e E., Ke mpen I., Z o on s J., A mpe B., Rod en burg T.B., Tuy t te n s F.A.M. (2015). Specific characteristics of the aviary housing system affect plumage condition, mortality and production in laying hens. Poultry Sci., 94: 2008-2017.

He erkens J.L.T., D e l e zi e E., R od enburg T.B., Ke mpen I., Z o on s J., A m pe B., Tuy t t e n s F.A.M. (2016 a). Risk factors associated with keel bone and foot pad disorders in laying hens housed in aviary systems. Poultry Sci., 95: 482-488.

H e erken s J.L.T., D e l e zi e E., A m p e B., R o d en burg T.B., Tuytten s F.A. (2016 b). Ramps and hybrid effects on keel bone and foot pad disorders in modified aviaries for laying hens. Poultry Sci., 95: 2479-2488.

He ge lund L.S., Ørens en J.T., Kjer J.B., Kristensen I.S. (2005). Use of the range area in organic egg production systems: effect of climatic factors, flock size, age and artificial cover. Brit. Poultry Sci., 46: 1-8.

Herbut E., Sosnówka-Czajka E., Rychlik I., S ok ołowicz Z. (2002). Welfare of chickens reared under different thermal conditions. Ann. Anim. Sci., Suppl. 1: 71-74.

Hester P.Y., Enneking S.A., Haley B.K., Cheng H.W., Einstein M.E., Rubin D.A. (2013 a). The effect of perch availability during pullet rearing and egg laying on musculoskeletal health of caged White Leghorn hens. Poultry Sci., 92: 1972-1980.

H e s t e r P.Y., En ne king S.A., J e ffe r s on - M o or e K.Y., E in s t e in M.E. (2013 b). The effect of perches in cages during pullet tearing and egg laying on hen performance, foot health, and plumage. Poultry Sci., 92: 310-320.

H e w lett S.E., Nordqu is t R.E. (2019). Effects of maternal care during rearing in White Leghorn and Brown Nick layer hens on cognition, sociality and fear. Animals, 9: 454.

Höglund J., N orden fors H., Uggla A. (1995). Prevalence of the red poultry mite, Dermanyssys gallinae, in different types of production systems for egg layers in Sweden. Poultry Sci., 74: 1793-1798.

H un n i ford M.E., Wi d ow s k i T.M. (2016). Rearing environment and laying location affect prelaying behavior in enriched cages. Appl. Anim. Behav. Sci., 181: 205-213.

H u n n i for d M.E., W i d o w s k i T.M. (2017). Nest alternatives: Adding a wire partition to the scratch area affects nest use and nesting behaviour of laying hens in furnished cages. Appl. Anim. Behav. Sci., 186: 29-34.

Hun n i ford M.E., Wi d o w s ki T.M. (2018). Curtained nests facilitate settled nesting behaviour of laying hens in furnished cages. Appl. Anim. Behav. Sci., 202: 39-45.

Hunniford M.E., Torrey S., Bédécarrats G., Duncan I.J., Widowski T.M. (2014). Evidence of competition for nest sites by laying hens in large furnished cages. Appl. Anim. Behav. Sci., 161: 95-104.

I c k e n W., Cavero D., S ch mutz M., Thurner S., Wendl G., Pre is ing e r R. (2008). Analysis of free range behaviour of laying hens and the genetic and phenotypic relationships with laying performance. Brit. Poultry Sci., 49: 533-541.

J a n c z a k A., Riber A.B. (2015). Review of rearing-related factors affecting the welfare of laying hens. Poultry Sci., 94: 1454-1469.

J on e s D.R., Gu ard J., G a s t RK., B u hr R.J., F e d ork a - C r a y P.J.,A b d o Z., P lu m b le e J.R., B ourassa D.V., Cox N.A., Rigsby L.L., Robison C.I., Regmi P., Karcher D.M. (2016). Influence of commercial laying hen housing systems on the incidence and identification of Salmonella and Campylobacter. Poultry Sci., 95: 1116-1124.

Kamil K.L., Bozkurt M., Herken E.N., Cinar M., Cath A.U., Bintas E., F thiye C. (2012). Effects of rearing systems on performance, egg characteristics and immune response in two layer hen genotype. Asian-Aust. J. Anim. Sci., 25: 559-568. 
Käppeli S., Gebhardt-Henrich S.G., Fröhlich E., Pfulg A., Schäublin H., Stoff e 1 M.H. (2011). Effects of housing, perches, genetics, and 25-hydroxycholecalciferol on keel bone deformities in laying hens. Poultry Sci., 90: 1637-1644.

K a r s t e n H.D., P a t t e r s on P.H., S t o u t R., C rew s G. (2010). Vitamins A, E and fatty acid composition of the eggs of caged hens and pastured hens. Renew. Agric. Food Syst., 25: 45-54.

Kilp in en O., Roepstorff A., P ermin A., Nørga ard-Ni e ls en G., Law s o n L.G., S i m o n s e n H.B. (2005). Influence of Dermanyssus gallinae and Ascaridia galli infections on behaviour and health of laying hens (Gallus gallus domesticus). Brit. Poultry Sci., 46: 26-34.

$\mathrm{K}$ le in T., Z e lt n e r E., H u ber-E i c her B. (2000). Are genetic differences in foraging behaviour of laying hen chicks paralleled by hybrid-species differences in feather pecking? Appl. Anim. Behav. Sci., 70: 143-155.

Kollenda E., Baldock D., Hiller N., Lorant A. (2020). Transitioning towards cage-free farming in the EU: Assessment of environmental and socio-economic impacts of increased animal welfare standards. Policy report by the Institute for European Environmental Policy, Brussels \& London, pp. 1-65.

Kucuky $1 \mathrm{lmaz}$ K., B ozkurt M., Herken E.N., C1nar M., Cat 11 A.U., Bintas E., Cov e n F. (2012). Effects of rearing systems on performance, egg characteristics and immune response in two layer hen genotype. Asian-Austral. J. Anim. Sci., 25: 559-568.

Larsen H., Cronin G.M., Gebhardt-Henrich G., Smith C.L., Hemsworth P.H., R a u 1 t J.L. (2017). Individual ranging behaviour patterns in commercial free-range layers as observed through RFID tracking. Animals, 7: 21.

Lay D.C., Fulton R.M., Hester P.Y., Karcher D.M., Kjaer J.B., Mench J.A., Mul lens B.A., N ewberry R.C., Nicol C.J., O'Sullivan N.P., Porter R.E. (2011). Hen welfare in different housing systems. Poultry Sci., 90: 278-294.

L e e Y.P., Chen T.L. (2007). Daytime behavioural patterns of slow-growing chickens in deep-litter pens with perches. Brit. Poultry Sci., 48: 113-120.

Leenstra F., Ten Napel J., Vis scher J., Van Sambeek F. (2016). Layer breeding programmes in changing production environments: a historic perspective. World's Poultry Sci. J., 72: 21-36.

Leinonen I., Williams A. G., Wis e man J., Guy J., K yriazakis I. (2012). Predicting the environmental impacts of chicken systems in the United Kingdom through a life cycle assessment: Egg production systems. Poultry Sci., 91: 26-40.

Leyendecker M., Hamann H., Hartung J., Kamphues J., Neuman U., Surie C., D i s 1 O. (2005). Keeping laying hens in furnished cages and an aviary housing system enhances their bone stability. Brit. Poultry Sci., 46: 536-544.

L i X., C h e n D., L i J., B a o J. (2016). Effect of furnished cage type on behavior and welfare of laying hens. Asian-Australas J. Anim. Sci., 29: 887-894.

M a h b o u b H.D.H., Mü 11 e r J., B or e 11 E. (2004). Outdoor use, tonic immobility, heterophil/lymphocyte ratio and feather condition in free-range laying hens of different genotype. Brit. Poultry Sci., 45: 738-744.

Matur E., Eras lan E., A ky azi I., Ekiz E.E., Es eceli H., Keten M., Metiner K., B a 1 a D.A. (2015). The effect of furnished cages on the immune response of laying hens under social stress. Poultry Sci., 94: 2853-2862.

Meng F., Ch en D., Li X., Li J., B a o J. (2015). Effects of large or small furnished cages on performance, welfare and egg quality of laying hens. Anim. Prod. Sci., 55: 793-798.

Meng F., Chen D., Li X., Li J., B a o J. (2017). The effect of large or small furnished cages on behaviors and tibia bone of laying hens. J. Vet. Behav., 17: 69-73.

M e s e r e t S. (2016). A review of poultry welfare in conventional production system. Livest. Res. Rural Dev., 28: 234.

M is hra A., K o en e P., S chouten W., S pruijt B., van B e e k P., M etz J.H. (2005). Temporal and sequential structure of behaviour and facility usage of laying hens in enriched environment. Poultry Sci., 84: 979-991.

Mugnai N., Sossidou E.N., Dal Bosco A., Ruggeri S., Mattioli S., Castellini C. (2013). The effects of husbandry system on the grass intake and egg nutritive characteristics of laying hens. J. Sci. food Agric., 94: 459-467. 
$\mathrm{Nag} l \mathrm{e}$ T.A., G lat z P.C. (2012). Free range hens use the range more when the outdoor environment is enriched. Asian-Australas. J. Anim. Sci., 25: 584-591.

$\mathrm{N}$ a s r M.A., M u r r e 11 J., N i c o 1 C.J. (2013). The effect of keel fractures on egg production, feed and water consumption in individual laying hens. Brit. Poultry Sci., 54: 165-170.

N a s r M.A.F., N i c o 1 C.J., W i 1 k in s L.J., M u r r e 11 J. (2014). The effect of two non-steroidal antiinflammatory drugs on the mobility of laying hens with keel bone fractures. Vet. Anaesth. Analg., 42: 197-204.

Neijat M., Casey-Trott T.M., Robin son S., Wid owski T.M., Kiarie E. (2019). Effects of rearing and adult laying housing systems on medullary, pneumatic and radius bone attributes in 73-wk old Lohmann LSL lite hens. Poultry Sci., 98: 2840-2845.

Ni el s e n B.L., Th o m s en M.G., S or e n s en P., You n g J.F. (2003). Feed and strain effects on the use of outdoor areas by broilers. Brit. Poultry Sci., 44: 161-169.

Oli v e ir a J.L., X in H., C h a i L., M ill m a n S.T. (2019). Effects of litter floor access and inclusion of experienced hens in aviary housing on floor eggs, litter condition, air quality, and hen welfare. Poultry Sci., 98: 1664-1677.

P e trik M.T., G u e r in M.T., W i d o w s k i T.M. (2015). On-farm comparison of keel fracture prevalence and other welfare indicators in conventional cage and floor-housed laying hens in Ontario, Canada. Poultry Sci., 94: 579-585.

P e t t e r s s o n I.C., W e e k s C.A., N o r m a n K.I., N i c o 1 C.J. (2017). The ability of laying pullets to negotiate two ramp designs as measured by bird preference and behaviour. Peer J., 5: e4069.

Pohle K., Cheng H.W. (2009). Furnished cage system and hen well-being: Comparative effects of furnished cages and battery cages on behavioral exhibitions in White Leghorn chickens. Poultry Sci., 88: 1559-1564.

Popova T., Petkov E., Ay as an T., Ig nat ova M. (2020). Quality of eggs from layers reared under alternative and conventional system. Braz. J. Poultry Sci., 22: 1-8.

R a u l t J.L., van d e Wouw A., Hem s w orth P. (2013). Fly the coop! Vertical structures influence the distribution and behaviour of laying hens in an outdoor range. J. Aust. Vet. Assoc., 91: 423-426.

R e g $\mathrm{m}$ i P., D e 1 a n d T.S., S t e i b e 1 J.P., R o b i s o n C.I., H a u t R.C., O r th M.W., K a r c h e r D.M. (2015). Effect of rearing environment on bone growth of pullets. Poultry Sci., 94: 502-511.

Regmi P., Nels on N., Haut R.C., Orth M.W., Karcher D.M. (2017). Influence of age and housing systems on properties of tibia and humerus of Lohmann White hens: Bone properties of laying hens in commercial housing systems. Poultry Sci., 96: 3755-3762.

Regmi P., Robison C.I., Jones D.R., Gast R.K., Tempelman R.J., Karcher D.M. (2018). Effects of different litter substrates and induced molt on production performance and welfare quality parameters of White Leghorn hens housed in multi-tiered aviary system. Poultry Sci., 97: 3397-3404.

Rehman M.S., Mahmud A., Mehmood S., Pasha T.N., Huss a in J., Khan M.T. (2017). Blood biochemistry and immune response in Aseel chicken under free-range, semi-intensive, and confinement rearing systems. Poultry Sci., 96: 226-233.

Riber A., Hinrichsen L. (2016). Feather eating and its associations with plumage damage and feathers on the floor in commercial farms of laying hens. Animal, 10: 1218-1224.

Richards G.J., Wilkins L.J., Knowles T.G., Booth F., Toscano M.J., Nicol C.J., B r o w n S.N. (2011). Continuous monitoring of pophole usage by commercially housed free-range hens throughout the production cycle. Vet. Rec., 169: 338

Riddle E.R., Ali A., Ca mpbell D., S i e g ford J.M. (2018). Space use by 4 strains of laying hens to perch, wing flap, dust bathe, stand and lie down. PloS One, 13(1): e0190532.

Rode nburg T.B., Tuy t ten s F., R e u K.D., Herm an L.R., Z o on s J., S on c k B. (2008). Welfare assessment of laying hens in furnished cages and non-cage systems: an on-farm comparison. Anim. Welfare, 17: 363-373.

Rodriguez-Aurrekoetxe a A., Estevez I. (2016). Use of space and its impact on the welfare of laying hens in commercial free-range system. Poultry Sci., 95: 2503-2513.

Rørvang M.V., Hinrichsen L.K., Riber A.B. (2019). Welfare of layers housed in small furnished cages on Danish commercial farms: The condition of keel bone, feet, plumage and skin. Brit. Poultry Sci., 60: 1-7. 
Rufener C., Baur S., Stratmann A., Tos c an o M.J. (2019). Keel bone fractures affect egg laying performance but not egg quality in laying hens housed in a commercial aviary system. Poultry Sci., 98: 1589-1600.

S a miullah S., Roberts R., Chous alka r K.K. (2014). Effect of production system and flock age on egg quality and total bacterial load in commercial laying hens. J. Appl. Poultry Res., 23: 59-70.

S chütz K.E., F orkman B., Jens en P. (2001). Domestication effects on foraging strategy, social behaviour and different fear responses: A comparison between the red junglefowl (Gallus gallus) and a modern layer strain. Appl. Anim. Behav. Sci., 74: 1-14.

S c hw a i g e r K., S c h m i e d E.M.V., B a u e r J. (2008). Comparative analysis of antibiotic resistance characteristics of gram-negative bacteria isolated from laying hens and eggs in conventional and organic keeping systems in Bavaria, Germany. Zoonoses Public Hlth., 55: 331-341.

Sh e rw in C.M., R i chards G.J., N i c o l C.J. (2010). Comparison of the welfare of layer hens in 4 housing systems in the UK. Brit. Poultry Sci., 51: 488-499.

Shimmura T., Eguchi Y., Uetake K., Tanaka T. (2008). Effect of separation of resources on behaviour of high-, medium- and low-ranked hens in furnished cages. Appl. Anim. Behav. Sci., 113: 74-86.

Shimmura T., Hirahara S., Azuma T., Suzuki T., Eguchi Y., Uetake K. (2010). Multifactorial investigation of various housing systems for laying hens. Brit. Poultry Sci., 51: 31-42.

S in g h M., C ow i e s o n A.J. (2013). Range use and pasture consumption in free-range poultry production. Anim. Prod. Sci., 53: 1202-1208.

S ingh M., Ruhnke I., d e Kon ing C., Drake K., S kerman A.G., H in ch G.N., Glatz P.C. (2017). Demographics and practices of semi-intensive free-range farming systems in Australia with an outdoor stocking density of $\leq 1500$ hens/hectare. PLoS One 12(10): e0187057.

Singh R., Cheng K.M., Silversides F.G. (2009). Production performance and egg quality of four strains of laying hens kept in conventional cages and floor pens. Poultry Sci., 88: $256-264$.

Sirovnik J., Stratmann A., Gebhardt-Henrich S.G., Würbel H., Toscano M.J. (2018). Feeding from perches in an aviary system reduces aggression and mortality in laying hens. Appl. Anim. Behav. Sci., 202: 53-62.

S k o morucha I., S os nów ka - C z a j k a E. (2017). Physiological parameters in broiler chickens reared under different housing systems during a period of high temperatures. Acta Sci. Pol. Zoot., 16: $25-34$.

Sosnówka-Czajka E., Skomorucha I., Herbut E., Muchacka R. (2006). Free-range and barn systems as related to productivity and welfare of broiler chickens of different commercial lines. World's Poultry Sci. J., Suppl., 62: 605.

S os nó w k a - C z a j k a E., S k o m or u ch a I., He rbu t E., M u c ha c k a R. (2007). Effect of management system and flock size on the behaviour of broiler chickens. Ann. Anim. Sci., 7: 329-336.

Sosnówka-Czajka E., Połtowicz K., Skomorucha I., Herbut E., Muchacka R. (2008). Effect of a dietary immunostimulant and housing system on immunological parameters in laying hens. World's Poultry Sci. J., Suppl., 64: 642.

S os nó w k a - Czajk a E., Herbut E., Sk o morucha I., M u c ha c k a R. (2011). Welfare levels in heritage breed vs. commercial laying hens in the litter system. Ann. Anim. Sci., 11: 585-595.

$\mathrm{S}$ t e e $\mathrm{n}$ f e ld t S., N i e l s e n B.L. (2015). Welfare of organic laying hens kept at different indoor stocking densities in a multi-tier aviary system. I: Egg laying, and use of veranda and outdoor area. Animal, 9: 1509-1517.

Stratmann A., Frohlich E.K.F., Harlandr-Matauschek A., Schrader L., Toscano M.J., Wurbel H., Gebhardt-Henrich S.G. (2015). Soft perches in an aviary system reduce incidence of keel bone damage in laying hens. PLoS One, 10:e0122568.

Stratmann A., Fröhlich E.K., Gebhardt-Henrich S.G., Harlander-Mataus chek A., Würbel H., To s c a no M.J. (2016). Genetic selection to increase bone strength affects prevalence of keel bone damage and egg parameters in commercially housed laying hens. Poultry Sci., 95: 975-984.

Struelens E., Tuyttens F.A.M., Duchateau L., Leroy T., Cox M., Vranken E., Buyse J., Z oon s J., B erckmans D., Ödberg F., S onck B. (2008). Perching behaviour 
and perch height preference of laying hens in furnished cages varying in height. Brit. Poultry Sci., 49: 381-389.

Tactacan G.B., Guenter W., Lew is N.J., Rodriguez-Lecompte J.C., House J.D. (2009). Performance and welfare of laying hens in conventional and enriched cages. Poultry Sci., 88: 698-707.

Ta u s o n R. (2002). Furnished cages and aviaries: production and health. World Poultry Sci. J., 58: 49-63.

Thorsten P., Scholz B., Schrader L. (2010). Perch material and diameter affects particular perching behaviours in laying hens. Appl. Anim. Behav. Sci., 127: 37-42.

Tos cano M., B ooth F., Richards G., Brown S., Karcher D., Tarlton J. (2018). Modeling collisions in laying hens as a tool to identify causative factors for keel bone fractures and means to reduce their occurrence and severity. PloS One, 13(7): e0200025.

Tuyttens F., Heyndrickx M., De Boeck M., Moreels A., Van Nuffel A., Van Poucke E., Van Coillie E., Van Dongen S., Lens L. (2005). Comparison of broiler chicken health and welfare in organic versus traditional production systems. Anim. Sci. Pap. Rep., 23, Suppl. 1: 217-222.

Uitdehaag K.A., Komen H., Rodenburg T.B., Kemp B., van Arendonk J. (2008). The novel object test as predictor of feather damage in cage-housed Rhode Island Red and White Leghorn laying hens. Appl. Anim. Behav. Sci., 109: 292-305.

Uitdehaag K.A., Rodenburg T.B., Bolhuis E.J., Decuypere E., Komen H. (2009). Mixed housing of different genetic lines of laying hens negatively affects feather pecking and fear related behaviour. Appl. Anim. Behav. Sci., 116: 58-66.

V ä is än en J., Håk a n s s on J., J e n s e n P. (2005). Social interactions in Red Junglefowl (Gallus gallus) and White Leghorn layers in stable groups and after re-grouping. Brit. Poultry Sci., 46: 156-168.

van Horne P.L.M., A chterbosch T.J. (2008). Animal welfare in poultry production systems: impact of EU standards on world trade. World's Poultry Sci. J., 64: 40-52.

van Staaveren N., Decina C., B a es C.F., Widowski T.M., B erke O., Ha rlander- Mat a u s che k A. (2018). A description of laying hen husbandry and management practices in Canada. Animals (Basel), 8: 114.

Vi 11 a nu e va S., A 1 i A.B.A., C a m p b e 11 D.L.M., S i e g ford J.M. (2017). Nest use patterns of egg laying and damage by 4 strains of laying hens in an aviary system. Poultry Sci., 96: 3011-3020.

W a 11 H. (2011). Production performance and proportion of nest eggs in layer hybrids housed in different designs of furnished cages. Poultry Sci., 90: 2153-2161.

Wang C., Ma Y., Huang Y., S u S., Wang L., S un Y., Wan Q., Li H., Z hang S., Øines Ø., $\mathrm{P}$ a n B. (2019). Darkness increases the population growth rate of the poultry red mite Dermanyssus gallinae. Parasit Vectors. 7: 213.

We i H., L i C., X in H., Li S., B i Y., L i X., L i J., Z hang R., B a o J. (2019). Keel fracture causes stress and inflammatory responses and inhibits the expression of the orexin system in laying hens. Animals (Basel), 9: 804.

We itzen bürger D., Vits A., H a mann H., D is 1 O. (2006). Evaluierung von Kleingruppenhaltungssystemen und ausgestalteten Käfigen hinsichtlich Brustbeindeformationen, Gefiederstatus, Krallenlänge und Körpermasse bei den Legelinien Lohmann Selected Leghorn und Lohmann Brown. Arch. Geflugelkd., 1: 89-102.

Wha y H.R., M a in D.C., Green L.E., H e aven G., How e 11 H., Morgan M., P e a r s o n A., W e b s t e r A.J. (2007). Assessment of the behavior and welfare of laying hens on free-range units. Vet. Rec., 161: 119-128.

Widowski T.M, Caston L.J., Hunniford M.E., Cooley L., Torrey S. (2017). Effect of space allowance and cage size on laying hens housed in furnished cages, Part I: Performance and well-being. Poultry Sci., 96: 3805-3815.

W i 1 k in s L.J., B row n S.N., Z i m m e r m a n P.H., L e e b C., N i c o 1 C.J. (2004). Investigation of palpation as a method for determining the prevalence of keel and furculum damage in laying hens. Vet. Rec., 155: 547-549.

Wilk ins L.J., Mc K instry J.L., Avery N.C., Knowles T.G., Brown S.N., Tarlton J.F., $\mathrm{N}$ i c o 1 C.J. (2011). Influence of housing system and design on bone strength and keel bone fractures in laying hens. Vet. Rec., 169: 414-420. 
Wiren A., Gunnars s on U., A nd ers s on L., J e n s e n P. (2009). Domestication-related genetic effects on social behavior in chickens - Effects of genotype at a major growth quantitative trait locus. Poultry Sci., 88: 1162-1166.

Yan F.F., Hester P.Y., Cheng H.W. (2014). The effect of perch access during pullet rearing and egg laying on physiological measures of stress in White Leghorns at 71 weeks of age. Poultry Sci., 93: $1348-1326$.

Yang H.M., Yang Z., Wang W., Wang Z.Y., Sun H.N., Ju X.J., Q i X.M. (2014). Effects of different housing systems on visceral organs, serum biochemical proportions, immune performance and egg quality of laying hens. Europ. Poultry Sci., 78, DOI: 10.1399/eps. 2014.48.

Received: 8 VI 2020

Accepted: 17 III 2021 